\title{
From the Complex Process of Gold Ions Recovery in New Antimicrobial Product
}

\author{
MARIA MIHAILESCU ${ }^{1}$, PETRU NEGREA ${ }^{1 *}$, NARCIS DUTEANU ${ }^{1}$, ADINA NEGREA ${ }^{1}$, MIHAELA CIOPEC ${ }^{1}$, VASILE GHERMAN ${ }^{1 *}$, \\ RAMONA BUZATU2, MARILENA MOTOC² \\ 1Politehnica University of Timisoara, Faculty of Industrial Chemistry and Environmental Engineering, 2 Victoriei Sq., 300006 \\ Timisoara, Romania \\ 2 Victor Babes University of Medicine and Pharmacy Timisoara, 2 Eftimie Murgu Sq., 300041, Timisoara, Romania
}

\begin{abstract}
Production of new antibacterial materials is really important due to high resistance bacteria at classical antibiotics. In presentstudy, using the adsorption process of gold ions loaded onto Amberlite XAD7-L-glutamic acid, antibacterial material wasproduced.The antibacterial activity of produced material was studied. In order to test this activity, frstly it was necessary to know the microbiological behaviour of Au(III), by running several toxicity tests. Synthesized material show good antibacterial activity against a broad spectrum of bacteria collected form BegaRiver. These studies were performed in order to find a new application of such materials as paints used as antibacterial agents in hospitals and for domestic use.
\end{abstract}

Keywords:Amberlite XAD7, antibacterial activities, gold, L-glutamic acid, toxicity

Gold extraction from different minerals is possible by using hydrometallurgical processes, although the traditional method is the cyanide extraction. Starting with the beginning of the XX century this method was unanimous accepted around the world[1].

Main disadvantage of such process is represented by higher toxicity of the cyanide, which can pollute the groundwater as a consequence of accidental leaking, representing a real threat to human health. Because of that it is really important to develop and implement new and clean technologies for gold production and recovery, like adsorption, thus avoiding the appearance of other residual contaminants. Materials with adsorbent properties used for gold recovery can be: active carbon particles [2], mesoporous adsorbents [3],chitosan, or chemical modified oxides $[4,5]$.

Field of materials engineering should consider aspects of antibacterial and bactericidal properties in the design of new materials for advanced biomaterial systems with medical applications [6].

Last decades brought a larger use of gold in fields like electronic or medical devices. Gold usage has a long history, for example it was used as medicine (Chrysitherapy) since antiquity. Gold has been used to treat diseases such as small pox, syphilis, skin ulcers and measles [7,8]. Its usage as medicine shows several benefits such as: stress and anxiety reduction, depression recovery, increased determination, increase of the intelligence coefficient until 20 units on Stanford-Binet scale, toning weakened organs, consequently improving the well-being of subjects. Since 70 's gold was included into the category of modern drugs used to ensure a good health of the joints especially in serious diseases such as rheumatoid arthritis [9]. At physical level gold is acting over the endocrine system and especially over the pituitary gland. Materials containing gold particles can be used in medical imaging and as well as into the cancer therapy [10]. Also, an enhanced and harmonized function of the endocrine gland which balancing secretion of different peptides - hormones, neurotransmitters - having a reviving and rejuvenating role was observed. Some tests proved that gold drugs strengthen the bone system and improve the sexual

\footnotetext{
*email: petru.negrea@upt.ro; ghermanvasile2000@yahoo.com;
}

function. On cardiac level - was noticed that gold present a good efficiency into the equilibration of cardiac function, myocardial toning, adjusting heart rate, adjusting blood pressure, sanguine flow, elimination of cardiomyopathy and heart failure[11-13].A big number of experimental studies proved that gold particles and gold ionic form present good antimicrobial and antibacterial effects[14]. It was proved that the cationic form of gold presents a moderate toxicity and the anionic form present zero toxicity[15].

Gold is probably the oldestmetal used as delivery vehicle for gene therapy, and one of the most advanced agents in all drug pharmacopoeias, its administration to humans being both deliberate and unintentional. The widest clinical application of gold (in rheumatoid arthritis) derives from a premise that was totally flawed. It has been used clinically to perform immune suppression buthas caused toxicity.

Despite the many known advantages of gold applications into different various economic areas, there is a serious concern about the toxicity of such materials on living organisms.

The toxicity of gold, unlike most drugs, is not predictably related to the levels it achieves in body tissues.As a result, gold pharmacology and toxicology is remarkably complex. Recent laboratory findings on gold metabolism have highlighted the important metabolic differences between the three oxidation states $(0, I$ and III). When placed in the context of a wealth of clinical experience, these findings provide useful information on its toxicology and mechanisms that involve the seemingly paradoxical behaviour of gold [16].

Toxic effect of gold materials onto the living organisms depends on the availability of materials. Bioavailability of gold particles is determined by adsorption, which depends on the particle size and superficial load. If materials exhibit a good bioavailability, they can also induce teratogenic effects [15].

In most cases, the toxicity tests of different materials are made using in vivo test onthe cells cultures. Thus, the goal of this study was to determine the minimum concentration at which gold ions become toxic for bacterial cultures. Based on these results same amount of gold was adsorbed onto the surface of Amberlite XAD7 
functionalized with L-glutamic acid, leading at new material (MD7-G-Au). In nest stage the antibacterial effect of produced material was tested.

\section{Experimental part}

Material and methods

Microbiological behaviour of Au(III). Toxicity tests

For establish the microbiological behaviour of $\mathrm{Au}(\mathrm{III})$, toxicity tests were performed using Au(III) solutions with concentrations of $50 \mathrm{mg} / \mathrm{L} ; 33 \mathrm{mg} / \mathrm{L} ; 25 \mathrm{mg} / \mathrm{L} ; 10 \mathrm{mg} / \mathrm{L}$; $5 \mathrm{mg} / \mathrm{L}$ and $2.5 \mathrm{mg} / \mathrm{L}$ obtained by dilution of a stock solution containing $100 \mathrm{mg} \mathrm{Au}(\mathrm{III}) / \mathrm{L}$. Toxicity tests were performed on heterotrophic bacteria cultures obtained from Bega River. Bacteria cultures were obtained on a solid nonselective grow th medium - Plate Count Agar, making two types of cultures: test cultures ( 3 repeats) -using test solutions with gold content and control cultures - without test solution. Inoculations method was performed by incorporation into Plate Count Agar growth medium, in sterile Petri dishes, which were incubated at $303 \mathrm{~K}$ for 48 $\mathrm{h}$. In sterile Petri dishes $1 \mathrm{~mL}$ of test solution, $1 \mathrm{~mL}$ of bacterial inoculum and $10 \mathrm{~mL}$ of Plate Count Agar growth medium were introduced. In control cultures, instead of the test solution, $1 \mathrm{~mL}$ of sterile distilled water was used.

Synthesis and characterization of the MD7-G-Au material In order to prepare the polymeric material with gold ions content used during antibacterial tests, Amberlite XAD7 resin (Sigma-Aldrich, Merck) was used as solid support. A well know amount of polymeric resin was functionalized with $\mathrm{L}$ - glutamic acid (Merck, Germany) which is acting as extractant. A proper amount of extractantwas dissolved in distilled water and mixed with support into the ration support: extractant-10:1. This mixture was kept in contact for $24 \mathrm{~h}$ at $298 \mathrm{~K}$, filtered and dried into the oven at $323 \mathrm{~K}$ for $24 \mathrm{~h}$. Further, this functionalized resin was used for gold recovery from cyanuric baths with initial gold concentration of $2 \mathrm{~g} / \mathrm{L}$, cyanide matrix being broken with aqua regia. In order to determine the amount of gold that can be loaded onto the Amberlite XAD7-L-glutamic acid (MD7-G) surface, the efficiency of the adsorption process of gold ions on its surface has been pursued. For this, the gold initial concentration was varying in the range $2.5 \mathrm{mg} \mathrm{Au}(\mathrm{III}) / \mathrm{L}$ and $150 \mathrm{mg} \mathrm{Au}(\mathrm{III}) / \mathrm{L}$. Adsorption process was conducted at $\mathrm{pH} 4$ in a thermostatic shaker at $298 \mathrm{~K}$, and $200 \mathrm{rpm}$ for $2 \mathrm{~h}$.

In samples, after filtration, the $A u(I I I)$ residual concentration was determined by atomic adsorption spectroscopy, using the atomic adsorption spectrophotometer, Varian SpectrAA $280 \mathrm{FS}$.

Obtained material was characterized by the energy dispersive X-ray spectroscopy (EDX), scanning electron microscopy (SEM).

Superficial charge of the material it is a key factor for adsorptive processes, so is important to determine the pZc.For these studies $0.1 \mathrm{M} \mathrm{NaCl}$ solution, varying $\mathrm{pH}$ in the range 1-14, using buffer solutions were used. Thus, $0.1 \mathrm{~g}$ MD7-G material over which $25 \mathrm{~mL}$ of NaClwas added and kept in contact for 1 hour in a J ulabo SW 23 water bath at $298 \mathrm{~K}$.
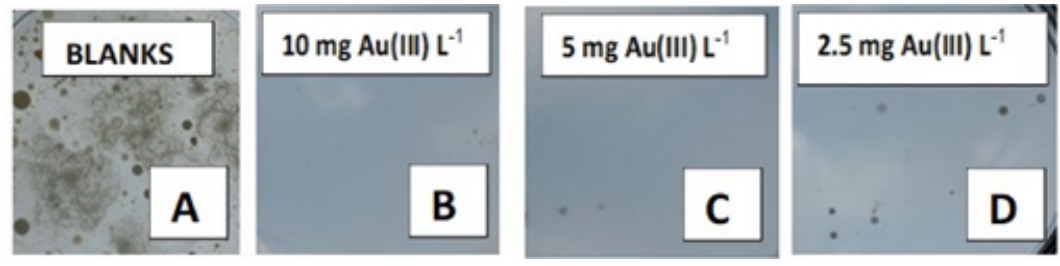

Fig. 1.Bacteria growth after $48 \mathrm{~h}$ incubation in control culture and tests culture 


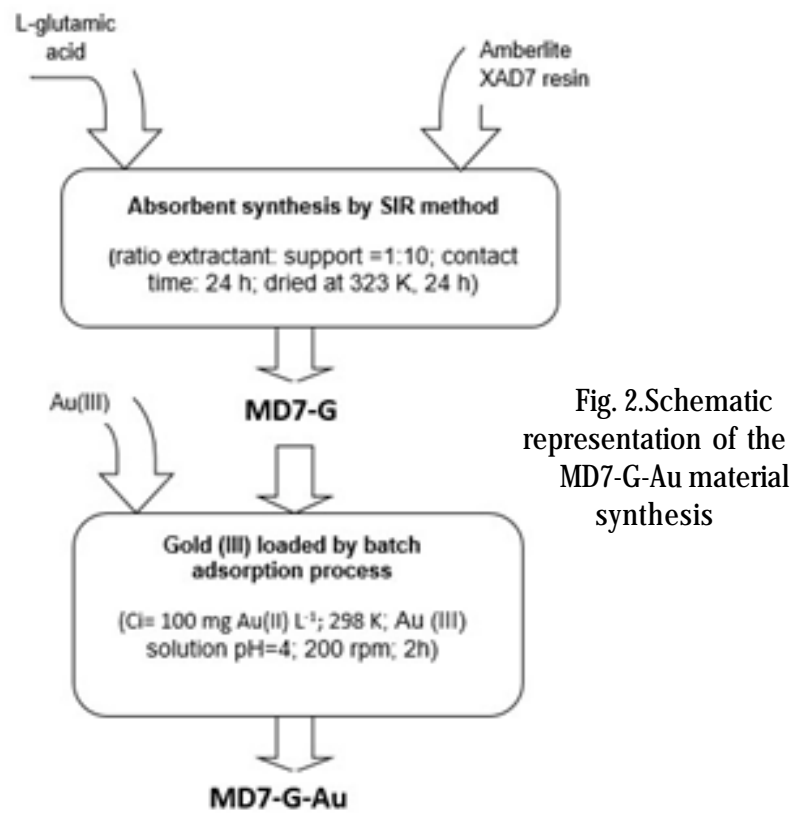

range 4-8 can be considered the equilibrium domain for the material. Produced adsorbent material has a pZc interval form 4 to 8 , which allows the use of this material in adsorption processes at $\mathrm{pH}$ 4-8. For this $\mathrm{pH}$ value, both cationic and anionic species can adsorb on the material surface. For $\mathrm{pH}$ values below the $\mathrm{pZcone}$, material surface will be positively charged due to $\mathrm{H}^{+}$protons adsorbed, favouring the adsorption of anionic species. For $\mathrm{pH}$ values above the pZcone, the material surface will be negatively charged due to $\mathrm{OH}$ adsorbed hydroxyl ions, favouring the adsorption of cationic species.

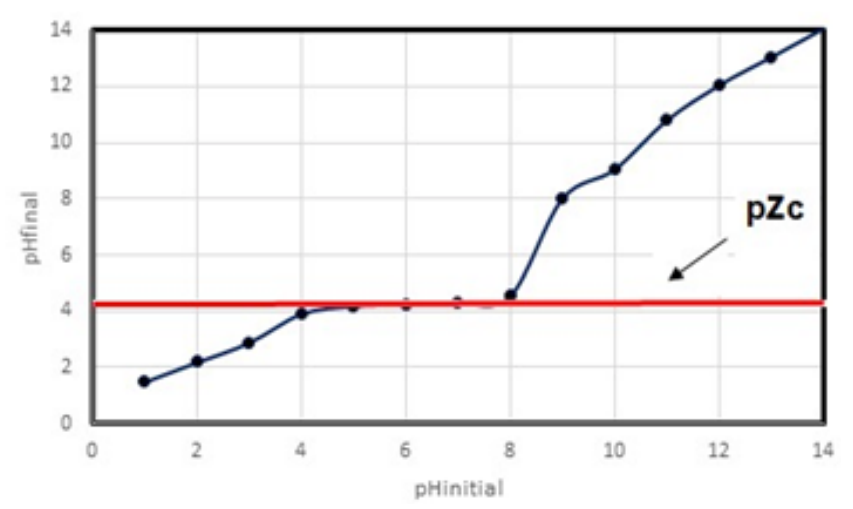

Fig. 3.pZc for MD7-G material

$\mathrm{Au}$ (III) loaded efficiency

Due to its antibacterial and antimicrobial effect, the gold amount existing in the biological environments is very important. The higher the gold amount is, the more benefits are, in terms of destroying bacteria.

The gold amount dependence loaded through adsorption on the MD7-G material surface of efficiency with which it manages to retain it is shown in figure 4.

It can be seen that with the increase in the gold concentration into the solution increase the gold load on the MD7-G synthesized material surface, increasing its efficiency of retaining gold. However, over $100 \mathrm{mg}$ of Au (III)/L the material'sefficiency decreases, so that for further studies regarding antibacterial effectbehaviour were used gold doped materials obtained for maximum efficiency.

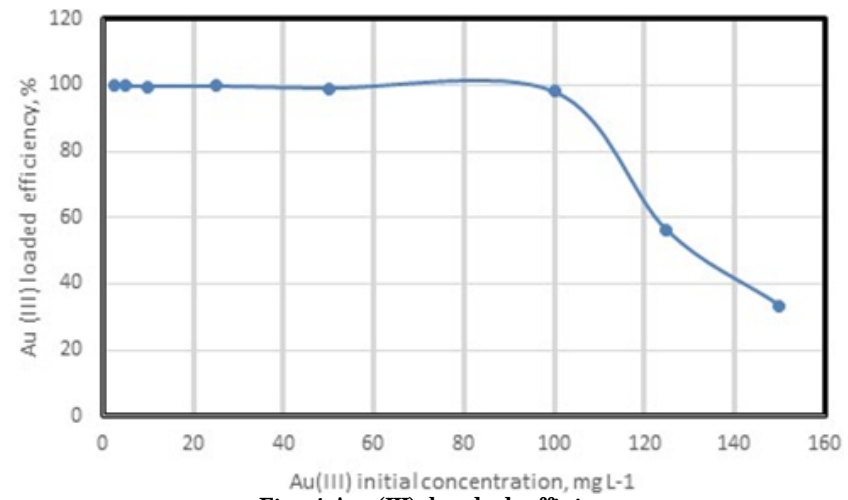

Fig. 4.Au (III) loaded efficiency

Characterization of the MD7-G-Au material

Energy dispersive $X$-ray spectroscopy (EDX) and scanning electron microscopy (SEM)

For morphological and elemental analysis of MD7-G$\mathrm{Au}$ in powder form, we used the scanning electron microscopy method, SEM and the energy dispersive X-ray spectroscopy, EDX.

The analysis was performed to prove the presence of gold particles in the synthesized material. The obtained results are presented in figure 5 and figure 6 .

From the presented dates it can be observed the gold presence onto MD7-G-Au material surface.

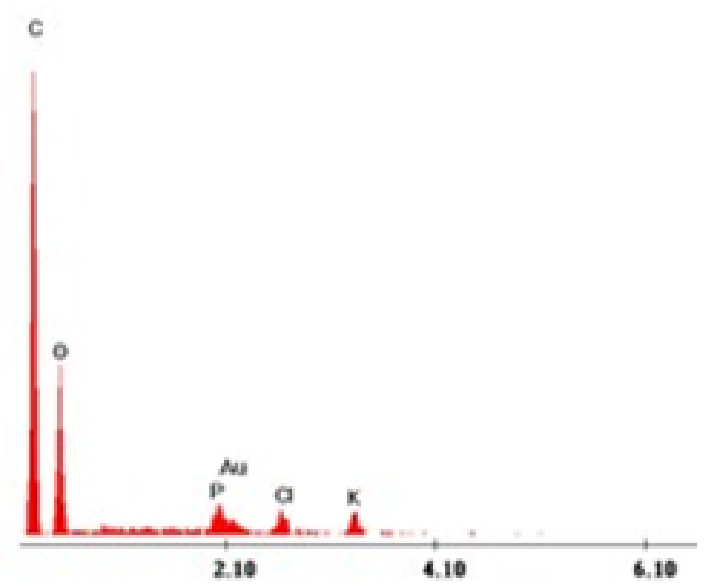

Fig. 5. Energy dispersive X-ray spectroscopy (EDX)
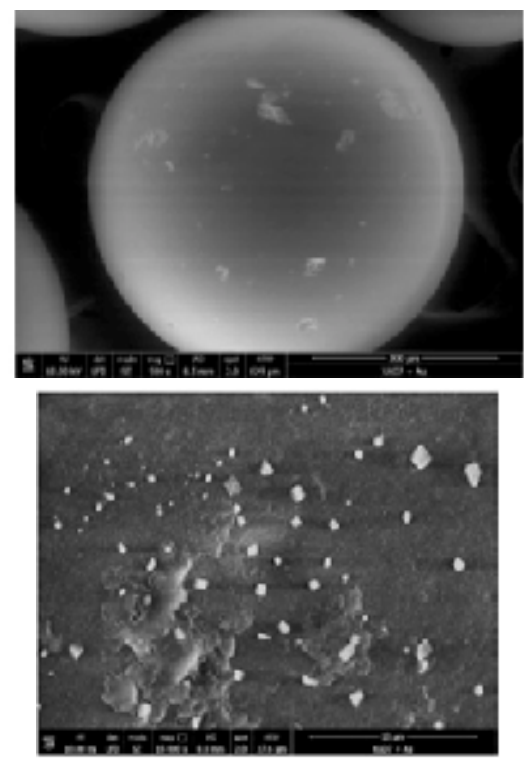

Fig. 6.Scanning electron microscopy (SEM) 


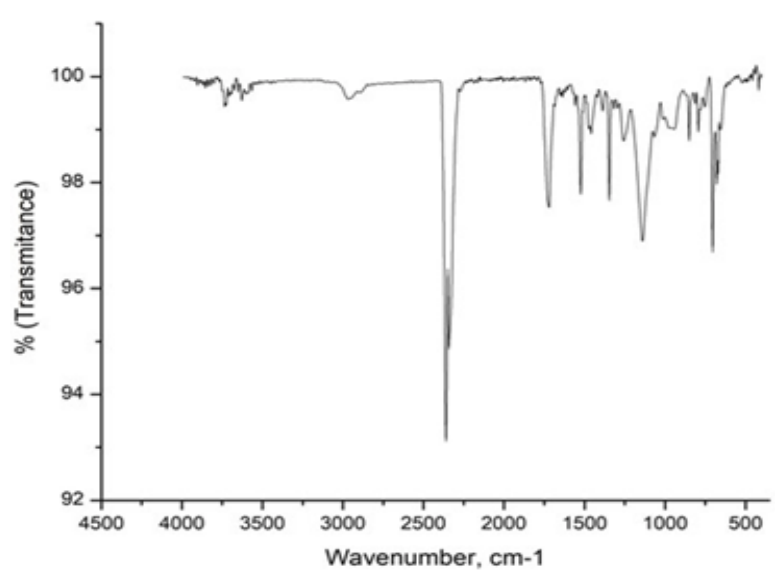

Fig. 7.FT-IR spectra from MD7-G-Au material

Infrared spectroscopy (FT-IR)

In order to highlight the groups specific to $\mathrm{Au}$ (III)doped MD7-G material, FT-IR spectroscopy was used. 7.

The specific spectrum of the material is shown in figure

From the FT-IR spectrum it can be observed that around the wavelengths of 1469 and $1389 \mathrm{~cm}^{-1}$, vibrations specific to the aliphatic $\mathrm{C}-\mathrm{H}$ group occur, and at 1700, 1200 and 1300 , and at the $1100 \mathrm{~cm}^{-1}$, vibrations specific to the bond $\mathrm{C}=0$. All of these vibrations being specific to the Amberlite XAD7 support, most of being powerful one[20,21].

It is also observed that around the wave number 1500 $1600 \mathrm{~cm}^{-1}$ vibrations specific to the $\mathrm{NH}_{2}$ groups from the extractant molecules[22,23], which reveal the functionalization of the polymer support with the amino acid specific groups.It can be observed that around 1600 $\mathrm{cm}^{-1}$ and $3400 \mathrm{~cm}^{-1}$ are vibrations specific to Au (III) particles [24].

\section{Antibacterial activities of the MD7-G-Au}

Taking into account the necessity to produce new antimicrobial products (for example dyes easy to use in hospitals) was tested the antimicrobial effect of the MD7G-Au produced material. During these tests, into the bacterial cultures the MD7-G-Au materials with different gold content were placed. Analysing obtained experimental data it was noticed that the MD7-G-Au material becomes toxic for bacterial cultures when tested sample contain 0.25 $\% \mathrm{Au}$ (III). Into the figure 8 the experimental data obtained for type 1test culture, where the MD7-G-Au material with $0.25 \% \mathrm{Au}(\mathrm{III})$ which was placed in five areas on Plate Count Agar growth medium and type 2 test culture, the MD7-GAu material with $0.25 \%$ Au (III) was mixed with $1 \mathrm{~mL}$ bacterial inoculum and $10 \mathrm{~mL}$ of Plate Count Agar growth medium are presented.

After $48 \mathrm{~h}$ incubation, a very good bacteria growth was observed in the control culture (fig. 8 A-C). In type 1 test culture, bacteria growth was observed just in marginal area of the growth medium where there is no the MD7-G-Au material (fig. $8 \mathrm{~A}$ ). In type 2 test culture, no bacteria growth was observed (fig. 8 B).

In conclusion, the toxicity of MD7-G-Au material is obvious (fig. 9).

In type 1 test culture (fig. 9.A), all areas with MD7-G-Au material with $0.25 \% \mathrm{Au}(\mathrm{III})$ are inhibitory for bacteria growth. In type 2 test culture, where the MD7-G-Au material with $0.25 \% \mathrm{Au}(\mathrm{III})$ are evenly distributed in the growth medium, there is a general inhibition of bacteria growth (fig. 9.B).
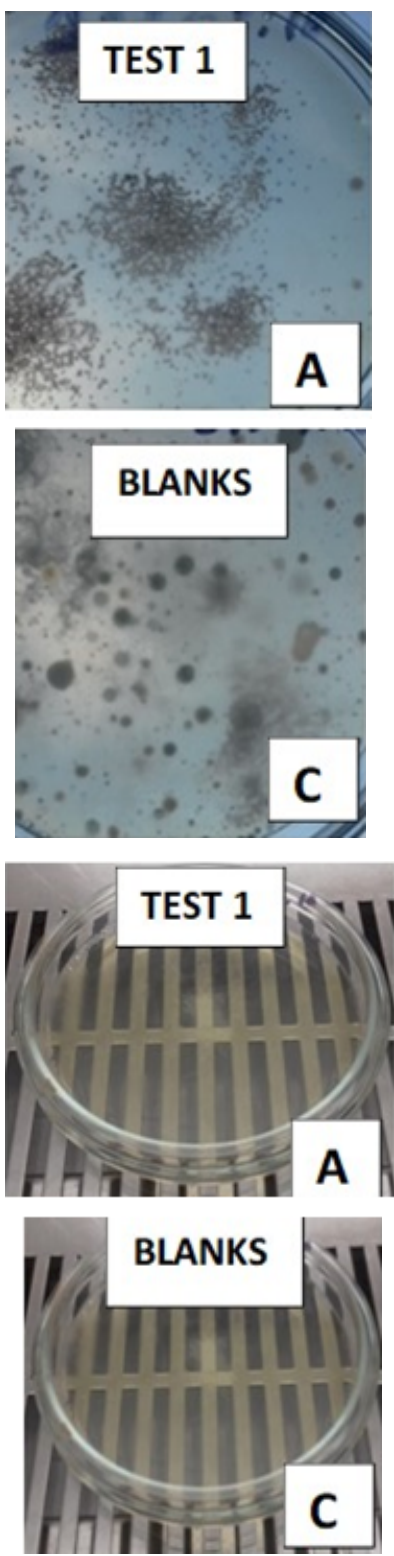

\section{Conclusions}

Present study proved the antibacterial effect of gold particles found into the solutions containing $A u(I I I)$ ions and also in case of gold particles loaded onto the functionalized Amberlite XAD7 resin with L-glutamic acid. Based on experimental data itwas proved thatno bacterial growth is observed when the gold concentration into the solution is $10 \mathrm{mg} \mathrm{Au}(\mathrm{III}) / \mathrm{L}$. When the MD7-G-Au material was used the antibacterial effect was obvious when the gold concentration had a value of $0.25 \% \mathrm{Au}(\mathrm{III})$.

In type 1 test culture, where the MD7-G-Au material with $0.25 \% \mathrm{Au}(\mathrm{III})$ which were placed in five areas on Plate Count Agar growth medium, has been observed an inhibitory effect for bacterial growth on all areas covered with the MD7-G-Au material.

In type 2 test culture, the MD7-G-Au material with $0.25 \%$ $\mathrm{Au}(\mathrm{III})$ mixed with $1 \mathrm{~mL}$ bacterial inoculum and $10 \mathrm{~mL}$ of Plate Count Agar growth medium, has been observed that the MD7-G-Au material are evenly distributed in the growth medium, which prove a general inhibition of bacteria growth. Antibacterial effect of gold particles may be due to the presence of gold ions on the surface of the polymeric resin as also due to the presence of $L$ - glutamic acid. Based on the obtained experimental data one can conclude that the MD7-G-Au material can be used into the production of different dyes used into the construction of smart building adaptable at climatic changes. 
Acknowledgement: This work was supported by a grant of the Romanian Ministry of Research and Innovation, CCCDI - UEFISCDI, project number PN-III-P1-1.2-PCCDI-2017-0391 / CIA_CLIM - Smart buildings adaptable to the climate change effects, within PNCDI III.

\section{References}

1.PEREA, C.G., RESTREPO, O.J., Hydrometallurgy,177, 2018, p. 79-85. 2.ZHANG, H., RITCHIE, I.M., LA BROOY, S.R., Hydrometallurgy, 72, nr. 3-4, 2004, p. 291-301.

3.LAM, K.F., FONG, C.M., YEUNG, K.L., MCKAY, G., Chem. Eng. J., 145, nr. 2, 2008, p. 185-195.

4.ARRASCUE, M.L., GARCIA, H.M., HORNA, O., GUIBAL, E., Hydrometallurgy, 71, 2003, p. 191-200.

5.BARBARA, W., WIESfAW, A., JERZY, W., Solvent Extr. Ion Exc.,26, 2008, p. 699-721.

6.GUZINSKA, K., KA•MIERCZAK, D., DYMEL, M., PABJANCZYKWLAZfO, E., BOGUÑ, M.,Mater. Sci. Eng., 93, 2018, p.800-808.

7.HUAIZHI, Z., YUANTAO, N., Gold Bull., 34, nr. 1, 2001, p. 24-29.

8.GIELEN, M., TIEKINK, E.R.T., Metallotherapeutic Drugs and MetalBased Diagnostic Agents: The Use of Metals in Medicine, Ed by J ohn Wiley and Sons, 2008.

9.MAINLAND, D.R., SUTCLIFFE, M.I., O'BRIEN, W.M., HEALEY. L.A., MIKKEISEN, W.M., WALACE, S.L., Arthritis \&Rheumatism, 16, nr. 3, 1973, p. 53-358.

10.MALA, R., RUBY CELSIA A.S., Toxicity of nanomaterials to biomedical applications-A review in Thomas, S., Balakrishnan, P., Sreekala, M.S, Fundamental Biomaterials: Ceramics ed by Woodhead Publishing, 2018.

11.KUMAR, S.S.R.C., Nanomaterialsfor cancer diagnosis, Ed. WileyVCH, 2007.
12.COMBS, R.J ., DENTINO, M.M., LEHRMAN, L., SZWED, J. ., Arthritis \&Rheumatism, 19, 1976, p. 936-938.

13.SIGLER, J.W., BLUHM, G.B., DUNCAN, H., SHARP, J.T., ENSIGN, D.C., MCCRUM, W.R., Ann Intern Med.,80, 1974, p. $21-26$.

14.ZHANG, Y., DASARI, T.P.S., DENG, H., HONGTAO, Y.U., J. Environ. Sci. Health.,Part C: Environmental Carcinogenesis and Ecotoxicology Reviews, 33, 2015, p. 286-327.

15.ALKILANY, A.M., BOULOS, S.P., LOHSE, S.E., THOMPSON, L.B., MURPHY, C.J ., Bioconjugate Chem., 25, 2014, p.1162-1171.

16.MERCHANT, B., Biologicals, 26, nr. 1,1998, p. 49-59.

17.NEGREA, A., CIOPEC, M., LUPA, L., MUNTEAN, C., LAZAU, R., NEGREA, P., Water pollution X, WIT Transaction on Ecology and Environment, 135, 2010, p. 117-129.

18.NEGREA, A., LUPA, L., CIOPEC, M., LAZIU, R., MUNTEAN, C., NEGREA, P., Adsorpt. Sci. Technol.,28, 2010, p. 467-480.

19.CEROVIC, L.J.S., MILONJIC, S.K., TODOROVIC, M.B., TRTANJ, M.I., POGOZHEV, Y.S., BLAGOVESCHENSKII, Y., CHEN, Y.N., CHAI, L.Y., SHU, Y.D., J. Hazard. Mater., 160, 2008, p. 168-172.

20.KATARINA, R.K., TAKAYANAGI, T., OSHIMA, M., MOTOMIZU, S., Anal. Chim. Acta.,558, 2006, p.246-253.

21.TANG, R., DU, Y., FAN, L., J.Polym. Sci., B 41, 2003, p. 993-997.

22.FUJ IWARA, K., RAMESH, A., MAKI, T., HASEGAWA, H., UEDA, K., J. Hazard.Mater.,146, 2007, p.39-50.

23.TU, Z., LU, S., CHANG, X., LI, Z., HU, Z., ZHANG, L., TIAN, H., Microchim.Acta,173, 2011, p.231-239.

24.ABDEL-RAOUF, N., AL-ENAZI, N.M., IBRAHEEM, I.B.M.,Arab. J Chem., 10, 2013, p. S3029-S3039.

Manuscript received: 23.07.2018 